\title{
TEMPERATURA DE ARMAZENAMENTO E QUALIDADE MICROBIOLÓGICA DO LEITE CRU GRANELIZADO NA REGIÃO DE RIO POMBA, MINAS GERAIS
}

\section{Storage temperature and microbiological quality of bulk raw milk in Rio Pomba, Minas Gerais}

\author{
Patrícia Rodriguez Condél, Cláudia Lúcia de Oliveira Pinto ${ }^{2}$, \\ Scarlet Ohana da Silva Gandra ${ }^{l}$, Roselir Ribeiro da Silva ${ }^{l}$, Maurilio Lopes Martins ${ }^{2 *}$
}

\section{RESUMO}

A refrigeração do leite cru em tanques de granelização representa um entrave na cadeia produtiva do leite associado à seleção de bactérias psicrotróficas deteriorantes com consequências negativas para a indústria. Objetivou-se avaliar a temperatura e a qualidade microbiológica de leite cru armazenado em 15 tanques de refrigeração do município de Rio Pomba, MG, nas estações do ano, entre outubro de 2016 e julho de 2017. A temperatura do leite em cada tanque foi determinada no momento da coleta das amostras. Posteriormente, realizou-se a contagem de microrganismos mesófilos aeróbios, psicrotróficos, psicrotróficos proteolíticos, psicrotróficos lipolíticos, psicrotróficos produtores de lecitinase e de Pseudomonas sp. Não houve diferença $(\mathrm{p}>0,05)$ de temperatura do leite no momento da coleta entre os 15 tanques de granelização, porém as médias das temperaturas foram acima de $4,0{ }^{\circ} \mathrm{C}$, portanto em desacordo com a Instrução Normativa n. ${ }^{\circ}$ 76. A contagem de microrganismos mesófilos aeróbios apresentou variação entre 3,4 a 6,8 Log UFC/mL, sendo que $42 \%$ das amostras não estavam em conformidade com o padrão legal. A contagem de microrganismos psicrotróficos apresentou variação entre 3,0 e 8,1 Log UFC/mL com média igual $(\mathrm{p}>0,05)$ à média da contagem de microrganismos mesófilos aeróbios. Mais de 50\% das amostras apresentaram contagens de Pseudomonas sp.

1 Instituto Federal de Educação, Ciência e Tecnologia do Sudeste de Minas Gerais - Campus Rio Pomba. Av. Dr. José Sebastião da Paixão, s/nº, Lindo Vale, 36180-000, Rio Pomba, MG, Brasil. E-mail: maurilio.martins@ifsudestemg.edu.br

2 Empresa de Pesquisa Agropecuária de Minas Gerais - EPAMIG SUDESTE, Viçosa, MG, Brasil.

* Autor para correspondência.

Recebido / Received: 04/10/2018

Aprovado / Approved: 08/01/2019 
acima de 4,0 Log UFC/mL. Concluiu-se que as condições higiênico-sanitárias na obtenção de leite cru no município de Rio Pomba, MG, apresentaram-se inadequadas, destacando-se, portanto, a importância da prevenção de contaminação do leite cru por meio da implementação das Boas Práticas na cadeia produtiva.

Palavras-chave: leite cru refrigerado; microbiota deterioradora; qualidade.

\begin{abstract}
The refrigeration of raw milk in bulk tanks represents an obstacle in the milk production chain associated with the selection of spoilage psychrotrophic bacteria with negative consequences for the industry. The aim of this work was to evaluate the temperature and microbiological quality of raw milk stored in 15 refrigeration tanks in the city of Rio Pomba, Minas Gerais, in the seasons, between October 2016 and July 2017. The temperature of the milk in each tank was determined at the time of sample collection. Subsequently, counts of aerobic mesophilic, psychrotrophic, proteolytic psychrotrophic, lipolytic psychrotrophic, lecithinase-producing psychrotrophic and Pseudomonas sp. were determined. There was no difference $(\mathrm{p}>0.05)$ in milk temperature at the time of collection among the 15 bulk tanks, however, the temperature averages were above $4.0^{\circ} \mathrm{C}$, therefore in disagreement with Normative Instruction $n .{ }^{\circ} 76$. The aerobic mesophilic count varied between 3.4 and 6.8 Log CFU/mL, and $42 \%$ of the samples did not comply with the legal standard. The count of psychrotrophic microorganisms presented variation between 3.0 and 8.1 Log CFU/mL with mean equal $(p>0.05)$ to the count of aerobic mesophilic microorganisms. More than $50 \%$ of the samples presented counts of Pseudomonas sp. above $4.0 \log \mathrm{CFU} / \mathrm{mL}$. It was concluded that the hygienic-sanitary conditions in the production of raw milk in the city of Rio Pomba, MG, were inadequate, thus highlighting the importance of contamination prevention of raw milk through the implementation of Good Practices in productive chain.
\end{abstract}

Keywords: cooled raw milk; spoilage microbiota; quality.

\section{INTRODUÇÃO}

Com o intuito de assegurar melhorias na qualidade do leite produzido no Brasil, o Ministério da Agricultura, Pecuária e Abastecimento (MAPA) regulamentou, por meio da Instrução Normativa n. ${ }^{\circ} 51$ (BRASIL, 2002), o uso do sistema de refrigeração do leite na propriedade rural, a sua coleta e o transporte a granel até a usina de beneficiamento, padrões microbiológicos, além de outras modificações. Por meio da Instrução Normativa n. ${ }^{\circ} 51$, estabeleceu-se que todo o leite produzido deveria ser mantido na propriedade em tan- ques de refrigeração a temperatura igual ou inferior a $4,0{ }^{\circ} \mathrm{C}$ por um período não superior a 48 horas, e, com temperatura máxima permitida, de $10,0{ }^{\circ} \mathrm{C}$ até sua chegada à indústria. Em virtude da dificuldade do produtor de se adequar aos novos padrões, a Instrução Normativa n. ${ }^{\circ} 51$ foi substituída pela Instrução Normativa n. ${ }^{\circ} 62$ do MAPA (BRASIL, 2011a), a qual foi revogada, atualmente, e substituída pela Instrução Normativa n. ${ }^{\circ} 76$, de 26 de novembro de 2018 (BRASIL, 2018a).

Em relação aos padrões microbiológicos, na Instrução Normativa n. ${ }^{0} 51$, foram 
fixadas, para as regiões Sudeste, CentroOeste e Sul, contagem padrão em placas de microrganismos mesófilos aeróbios de, no máximo, $10^{6} \mathrm{UFC} / \mathrm{mL}$, com redução gradativa a partir de 2008 , com limite de conjunto para $300.000 \mathrm{UFC} / \mathrm{mL}$ a partir de 01/07/2011. Porém, houve dificuldade por parte dos produtores em atingir estes parâmetros, em consequência, houve prorrogação dos prazos por meio da Instrução Normativa n. ${ }^{\circ} 32$ (BRASIL, 2011b), Instrução Normativa n. ${ }^{\circ} 62$ (BRASIL, 2011a), Instrução Normativa n. ${ }^{\circ} 7$ (BRASIL, 2016), com manutenção do limite de contagem padrão em placas de 300.000 $\mathrm{UFC} / \mathrm{mL}$ até 30/06/2018 para as regiões Sul, Sudeste e Centro-Oeste, e posteriormente pela regulamentação da Instrução Normativa n. 31 de 29 de junho de 2018 (BRASIL, 2018b) que alterou estes valores, prorrogando a contagem padrão em placas de aeróbios mesófilos, para $300.000 \mathrm{UFC} / \mathrm{mL}$ para todas as regiões do Brasil a partir de 30/06/2019, e contagem padrão em placas de no máximo 100.000 UFC/mL a partir de 01/07/2019, também para todas as regiões do Brasil. No entanto, de acordo com a Instrução Normativa n. ${ }^{\circ} 76$ (BRASIL, 2018a), publicada recentemente, passou a vigorar para leite cru refrigerado de tanques individuais ou de uso comunitário, contagem padrão em placas de $300.000 \mathrm{UFC} / \mathrm{mL}$ e antes de seu processamento no estabelecimento beneficiador, o limite máximo foi estabelecido em até $900.000 \mathrm{UFC} / \mathrm{mL}$, para todas as regiões do Brasil.

Entretanto, existem negligências quanto à implementação das boas práticas de produção, incluindo tempo e temperatura nos tanques de expansão, o que impede a obtenção do leite de acordo com os padrões de qualidade (BERSOT et al., 2010; SEQUETTO et al., 2017). A presença de bactérias contaminantes no leite como as psicrotróficas é um dos principais fatores limitantes para a obtenção de leite e de produtos lácteos de boa qualidade. Esses microrganismos multiplicam-se a $7,0{ }^{\circ} \mathrm{C}$ ou em temperaturas inferiores independente de sua temperatura ótima de crescimento por possuírem mecanismos específicos de adaptação ao frio. Além disso, produzem enzimas proteolíticas, lipolíticas e lecitinases termorresistentes que são associadas à perda de qualidade e de rendimento, coagulação doce do leite Ultra High Temperature - UHT, redução da vida útil dos produtos lácteos, produção de compostos associados a sabores amargos e de ranço no leite e derivados (COUSIN, 1982; PINTO, 2004; PINTO et al., 2014; OLIVEIRA et al., 2015; MACHADO et al., 2017), o que reflete em prejuízos econômicos consideráveis ao longo da cadeia produtiva.

Portanto, uma das análises utilizadas para avaliar a qualidade microbiológica do leite cru é a contagem padrão em placas de microrganismos mesófilos aeróbios, a qual tem como objetivo fornecer resultados indicativos dos cuidados com a higiene no processo de obtenção e estocagem da matériaprima na propriedade rural (BRITO, 2010).

Considerando a importância de dar continuidade às pesquisas que vêm sendo realizadas, ao longo dos últimos dez anos, sobre a qualidade microbiológica do leite cru, no Instituto Federal do Sudeste de Minas Gerais, Campus Rio Pomba, em parceria com a Empresa de Pesquisa Agropecuária de Minas Gerais (EPAMIG/Sudeste), às quais têm contribuído para a geração e a difusão de conhecimentos na área de laticínios e formação de recursos humanos (CANUTO et al., 2016), objetivou-se avaliar, sazonalmente, a qualidade microbiológica do leite cru granelizado, conservado em tanques de granelização instalados no município de Rio Pomba, Minas Gerais. 


\section{MATERIAL E MÉTODOS}

\section{Coleta das amostras}

Entre outubro de 2016 e julho de 2017, foram coletadas, assepticamente, amostras de $200 \mathrm{~mL}$ de leite cru refrigerado, que era armazenado por, aproximadamente, 48 horas em 15 tanques de granelização. Dessa forma, a cada estação do ano, 15 amostras foram coletadas, uma em cada tanque, em um total de 60 amostras. Determinou-se a temperatura do leite no momento de cada coleta. Posteriormente, as amostras foram transferidas, assepticamente, dos tanques de expansão para frascos de vidro esterilizados e, durante o transporte, foram acondicionados em caixas térmicas, em banho de gelo reciclável, com temperatura inferior a $4,0{ }^{\circ} \mathrm{C}$ e transportadas ao Laboratório de Microbiologia de Alimentos para determinação das contagens bacterianas.

\section{Contagem microbiana das amostras de leite cru refrigerado}

Foram realizadas diluições decimais sucessivas das amostras de leite cru refrigerado, as quais foram plaqueadas em Ágar Padrão para Contagem (PCA - Acumédia, Michigan, USA), para determinação da contagem de bactérias mesófilas aeróbias após incubação, a $32,0{ }^{\circ} \mathrm{C}$, por 48 horas (MORTON, 2001).

As diluições das amostras de leite cru também foram plaqueadas em Ágar Caseinato para Métodos Padronizados (SMCA - Himedia, Mimbai, Índia), para contagem de bactérias psicrotróficas (COUSIN et al., 2001) e psicrotróficas proteolíticas viáveis (MARCY et al., 2001), em PCA adicionado de $1 \%$ de tributirina para contagem de bactérias psicrotróficas lipolíticas e em
Ágar Tripticaseína de Soja (TSA - Kasvi, Pinhais, Paraná, Brasil), adicionado de 5\% de emulsão gema de ovo para contagem de bactérias psicrotróficas produtoras da enzima lecitinase, com incubação, a 6,5 $\pm 0,5^{\circ} \mathrm{C}$, por 10 dias (HAAS, 2001). A contagem de Pseudomonas spp. foi realizada após 72 horas de incubação, a 22,0 ${ }^{\circ} \mathrm{C}$, em Ágar Base para Pseudomonas (20 g/L de peptona de caseína, $10 \mathrm{~g} / \mathrm{L}$ de sulfato de potássio, 1,4 g/L de cloreto de magnésio, 13,6 g/L e ágar, 0,025 g/L de Irgasan e $20 \mathrm{~mL} / \mathrm{L}$ de glicerol (Interlab, São Paulo, Brasil)), suplementado com os agentes seletivos cetrimide $10 \mathrm{mg} / \mathrm{L}$, fucidina $10 \mathrm{mg} / \mathrm{L}$ e cefalosporina $50 \mathrm{mg} / \mathrm{L}$ (Merck ${ }^{\circledR}$, Barueri, São Paulo) (COUSIN; BRAMLEY, 1981). Essa contagem não foi realizada na primavera.

\section{Análises Estatísticas}

Para avaliação da temperatura, utilizouse Delineamento Inteiramente Casualizado (DIC) e análise de variância, sendo as médias comparadas pelo teste de Tuckey $(\mathrm{p}<0,05)$.

Duas análises descritivas foram realizadas: uma para avaliar a temperatura de coleta e a outra para avaliar o percentual de amostras coletadas em tanques de granelização de leite cru quanto às faixas de contagens dos diferentes grupos de microrganismos.

Além disso, os dados referentes às contagens microbianas das amostras, foram analisados comparando-se as médias entre tanques em cada estação do ano, em esquema fatorial e os resultados analisados por meio da análise de variância fatorial 4x5 (4 estações do ano e 5 grupos de microrganismos) e as médias dos tratamentos comparadas pelo teste de Tukey $(\mathrm{p}<0,05)$.

Para as análises estatísticas foi usado o software Statistica (TIBCO, 2017). 


\section{RESULTADOS E DISCUSSÃO}

\section{Temperatura das amostras no momento da coleta}

Não houve diferença $(\mathrm{p}>0,05)$ de temperatura do leite cru no momento da coleta entre os 15 tanques de expansão nas estações do ano (Figura 1). Porém, as médias das temperaturas em cada estação foram superiores a $4,0{ }^{\circ} \mathrm{C}$ (Figura 1), estando em desacordo com a exigência legal citada na Instrução Normativa n. ${ }^{\circ} 76$ (BRASIL, 2018a).

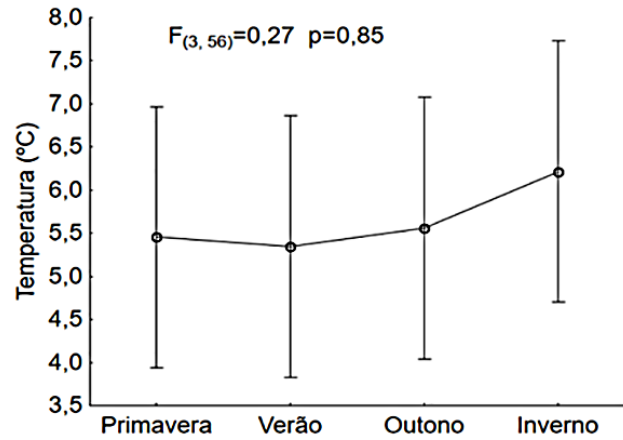

Figura 1 - Temperatura média $(\mathrm{n}=15)$ do leite cru no momento das coletas realizadas em tanques de granelização, nas diferentes estações do ano entre outubro de 2016 e julho de 2017 . O intervalo de confiança $(\mathrm{p}<0,05)$ é representado pelas linhas verticais.
Segundo Sequetto et al. (2017), o armazenamento do leite cru refrigerado na fonte de produção de acordo com a Instrução Normativa . $^{\circ} 62$ (BRASIL, 2011a), revogada recentemente por BRASIL (2018a), traz entre seus objetivos principais, a redução de perdas econômicas pela atividade acidificante de bactérias mesófilas. Entretanto, a estocagem de leite cru por períodos superiores a 48 horas, obtido em condições precárias, permite a seleção de bactérias psicrotróficas relacionadas a problemas tecnológicos e econômicos na indústria de laticínios.

Constatou-se que $60 \%$ das amostras de leite cru coletadas em tanques de granelização apresentaram temperaturas inferiores a $4,0{ }^{\circ} \mathrm{C}$ no outono (Figura 2). Entretanto, nas demais estações, apenas 33,3\% das amostras atenderam a exigência legal (BRASIL, 2018a) para armazenamento do leite cru refrigerado (Figura 2). Verificou-se também, que no verão, 53,3\% das amostras tiveram temperaturas entre 4,1 a $7,0{ }^{\circ} \mathrm{C}$, seguidos da primavera, inverno e outono, com 40,0\%, 33,3\% e $13,3 \%$, respectivamente (Figura 2 ). Além disso, mais da metade das amostras do verão não atenderam à exigência legal, situação que compromete a qualidade final dos derivados lácteos.

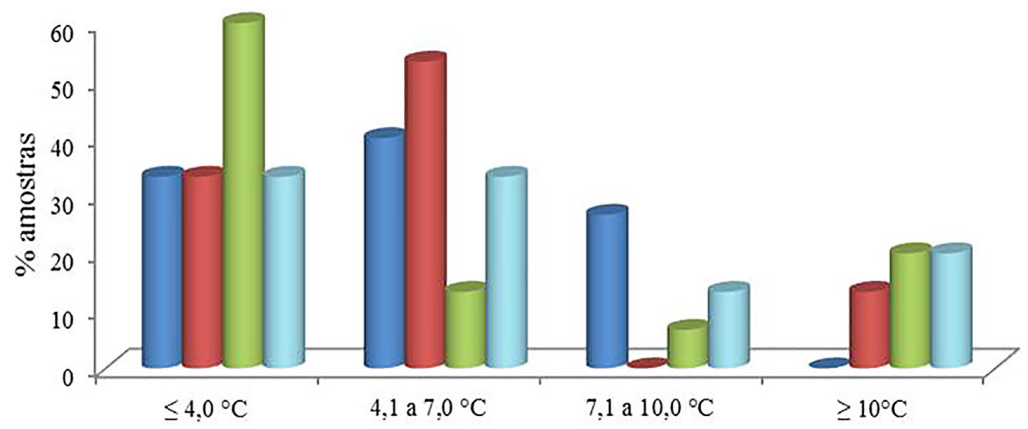

Faixas de temperatura

Figura 2 - Temperatura do leite cru granelizado no momento da coleta. ( $\square$ ) primavera, ( $\square$ ) verão, ( $\square$ ) outono e ( $\square$ ) inverno. 
Mais de 26\% das amostras na primavera tiveram temperaturas acima de $7,0{ }^{\circ} \mathrm{C}$ no momento da coleta e $20 \%$ das amostras no outono e inverno apresentaram temperaturas acima de $10,0{ }^{\circ} \mathrm{C}$ (Figura 2). Os motivos das temperaturas elevadas podem estar relacionados a fatores como a capacidade de refrigeração dos tanques não ser eficiente $\mathrm{o}$ suficiente para atingir a temperatura de $4,0^{\circ} \mathrm{C}$, por um período de, no máximo, três horas após a ordenha (BRASIL, 2018a), ou, no momento da coleta, o leite do dia anterior estar sendo misturado ao leite recém-ordenhado, ou até mesmo, por motivos isolados, como falta de energia elétrica. A refrigeração do leite cru está estreitamente relacionada à manutenção da qualidade do produto que, quando obtido em condições higiênicas satisfatórias e transportado adequadamente até às indústrias, atende satisfatoriamente ao processamento.

Em geral, 60\% das amostras de leite cru granelizado apresentaram temperatura acima de $4,0^{\circ} \mathrm{C}$. Ao avaliar a temperatura do leite em 17 tanques de refrigeração instalados em propriedades rurais no município de Rio Pomba, Minas Gerais, Costa (2014) constatou que mais de $80,0 \%$ das amostras tiveram valores de temperatura acima do permitido pela Instrução Normativa n. ${ }^{\circ} 62$ (BRASIL, 2011a). De acordo com o autor, a demora no resfriamento do leite pelo tanque, pode ocasionar a multiplicação de microrganismos e causar prejuízos relacionados à perda de estabilidade das caseínas do leite e aceleração de sua acidificação pela microbiota mesofílica.

Batista (2015) observou temperaturas acima de $4,0{ }^{\circ} \mathrm{C}$ no armazenamento de leite cru em todas as estações do ano. Segundo o autor, uma vez que o leite cru, obtido em más condições de higiene, permanece por até cinco horas sob refrigeração, poderá ocorrer o aumento de, aproximadamente, um ciclo logarítmo na contagem de microrganismos psicrotróficos, pelo fato destas bactérias gastarem, em média, de 6 a 9 horas, para com- pletar a divisão celular a $7,0{ }^{\circ} \mathrm{C}$ ou menos

\section{Qualidade microbiológica das amostras de leite cru refrigerado}

Constatou-se que no inverno $40,0 \%$ das amostras de leite cru apresentaram contagens de microrganismos mesófilos aeróbios entre 3,0 a 4,0 Log UFC/mL (Figura 3a), estando de acordo com a Instrução Normativa n. ${ }^{\circ} 76$ (BRASIL, 2018a) que estabelece contagem de $300.000 \mathrm{UFC} / \mathrm{mL}$, que corresponde a aproximadamente, 5,48 Log UFC/mL. Ribeiro Neto et al. (2012) afirmaram que resultados de contagem padrão em placas de microrganismos mesófilos aeróbios inferiores a 4,3 Log UFC/mL indicam boas práticas de higiene na obtenção do leite cru.

Também foram encontradas faixas de contagens de microrganismos mesófilos aeróbios entre 4,1 a 5,0 Log UFC/mL no verão, outono e inverno em $46,7 \%, 46,7 \%$ e $33,3 \%$ das amostras, respectivamente (Figura 3a). Essa faixa de contagem ainda é permitida na legislação vigente. Entretanto, na primavera, mais de $50 \%$ das amostras não estavam em conformidade com Brasil (2018a) e destas, mais de $30 \%$ apresentaram contagens acima de 6,1 Log UFC/mL (Figura 3a). No verão, também foram observadas contagens acima do permitido em $40 \%$ das amostras (Figura 3a). Considerando todas as estações do ano, $42 \%$ das amostras não atenderam aos requisitos estabelecidos por Brasil (2018a).

Em geral, as contagens de microrganismos mesófilos aeróbios variaram entre 3,4 a 6,8 Log UFC/mL. O motivo desta variação pode estar relacionado às situações encontradas durante as coletas. Observou-se que parte dos produtores não adotava as boas práticas de produção, não demonstrava muito interesse em mudar sua rotina e mostravamse insatisfeitos com o valor pago pelo litro de leite, mesmo estando cientes que o leite é pago pela qualidade que chega às indústrias. 


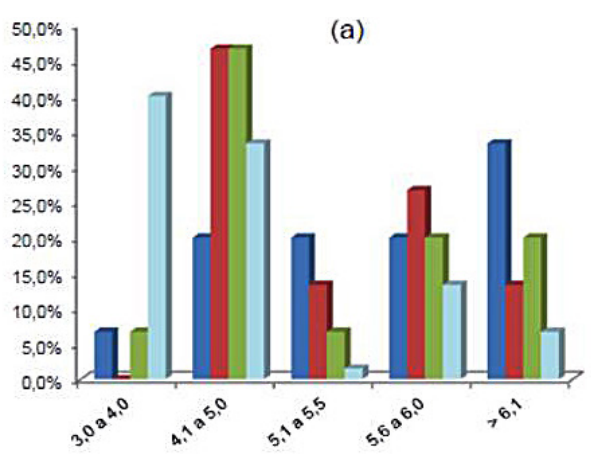

(c)

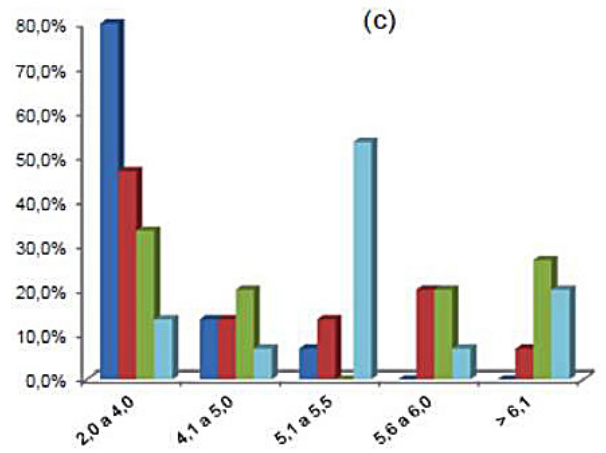

(e)

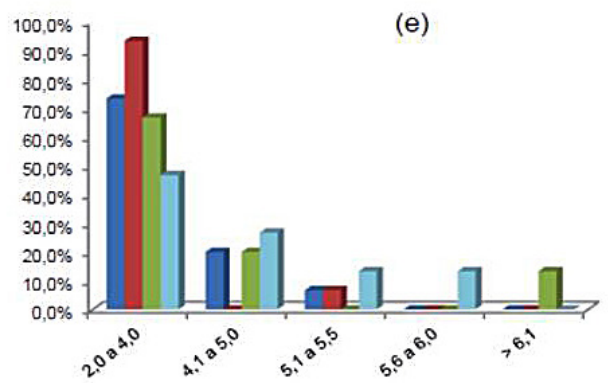

(b)

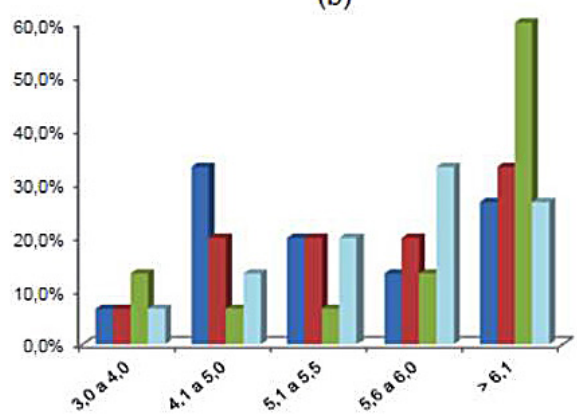

(d)

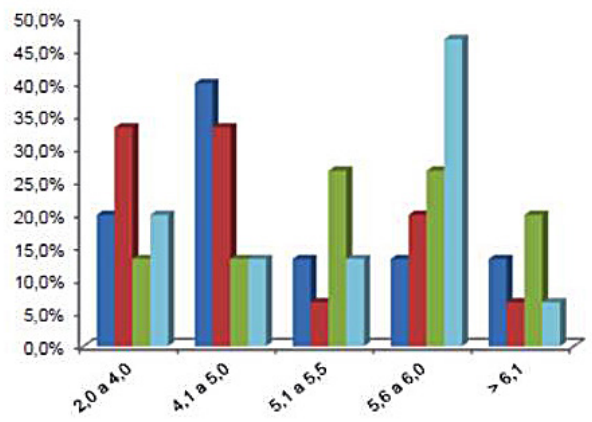

(f)

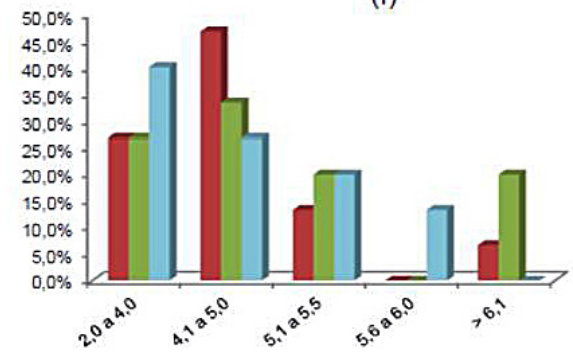

Figura 3 - Percentual de amostras de leite cru coletadas dos 15 tanques de refrigeração na ( $\square$ ) primavera, ( $\square$ ) verão, ( $\square$ ) outono e ( $\square$ ) inverno, agrupadas em diferentes faixas de contagens (Log UFC/mL). (a) Mesófilos aeróbicos, (b) psicrotróficos, (c) psicrotróficos proteolíticos, (d) psicrotróficos lipolíticos, (e) psicrotróficos produtores de lecitinase e (f) Pseudomonas ssp.

Verificou-se, também, que as ordenhas eram realizadas próximas aos tanques de refrigeração, que não eram adequadamente instalados e higienizados (Figura 4 A, B e C). Em contrapartida, haviam produtores preocupados com a sanidade do rebanho e com a obtenção de leite de qualidade.
Em registros fotográficos das instalações e condições higiênico-sanitárias dos tanques de granelização (Figura 4), alguns foram selecionados para evidenciar as médias de contagens de microrganismos mesófilos aeróbios e sua influência relacionada à condição de higiene do local de armazenamen- 
to do tanque. Observou-se que o tanque (D), estava instalado corretamente, devidamente higienizado, e, portanto, foi o que apresentou menor média de contagem para este grupo microbiano, ressaltando, portanto, resultados positivos quando são adotadas práticas de higiene e instalação adequada.

Os resultados de contagem padrão em placas de microrganismos mesófilos aeróbios encontrados corroboram com os observados por Costa (2014), também realizado no município de Rio Pomba, MG. Este autor constatou que apenas $17,6 \%$ das amostras estavam de acordo com os padrões legais. $\mathrm{O}$ autor afirmou ainda que, do ponto de vista tecnológico, a obtenção de matéria-prima de qualidade é um dos maiores problemas no desenvolvimento da indústria laticinista no Brasil.
Sequetto et al. (2017), ao avaliar a qualidade microbiológica de leite cru de 10 propriedades rurais da Zona da Mata mineira, para mesófilos aeróbios, constatou que 40\% das amostras não estavam de acordo com a legislação (BRASIL, 2018a). Para os autores, o controle inadequado da temperatura do leite durante sua estocagem pode contribuir para o desenvolvimento destes microrganismos.

A contagem de microrganismos psicrotróficos do leite cru variou entre 3,0 a $8,1 \mathrm{Log}$ UFC/mL (Figura $3 b$ ) e para microrganismos psicrotróficos proteolíticos, entre 2,0 a 7,1 Log UFC/mL (Figura 3c). Não existe legislação vigente que estabeleça padrões para estes grupos de microrganismos, porém, Cousin (1982) destaca que é imprudente o processamento de derivados lácteos a partir de leite cru com contagem de microrganismos
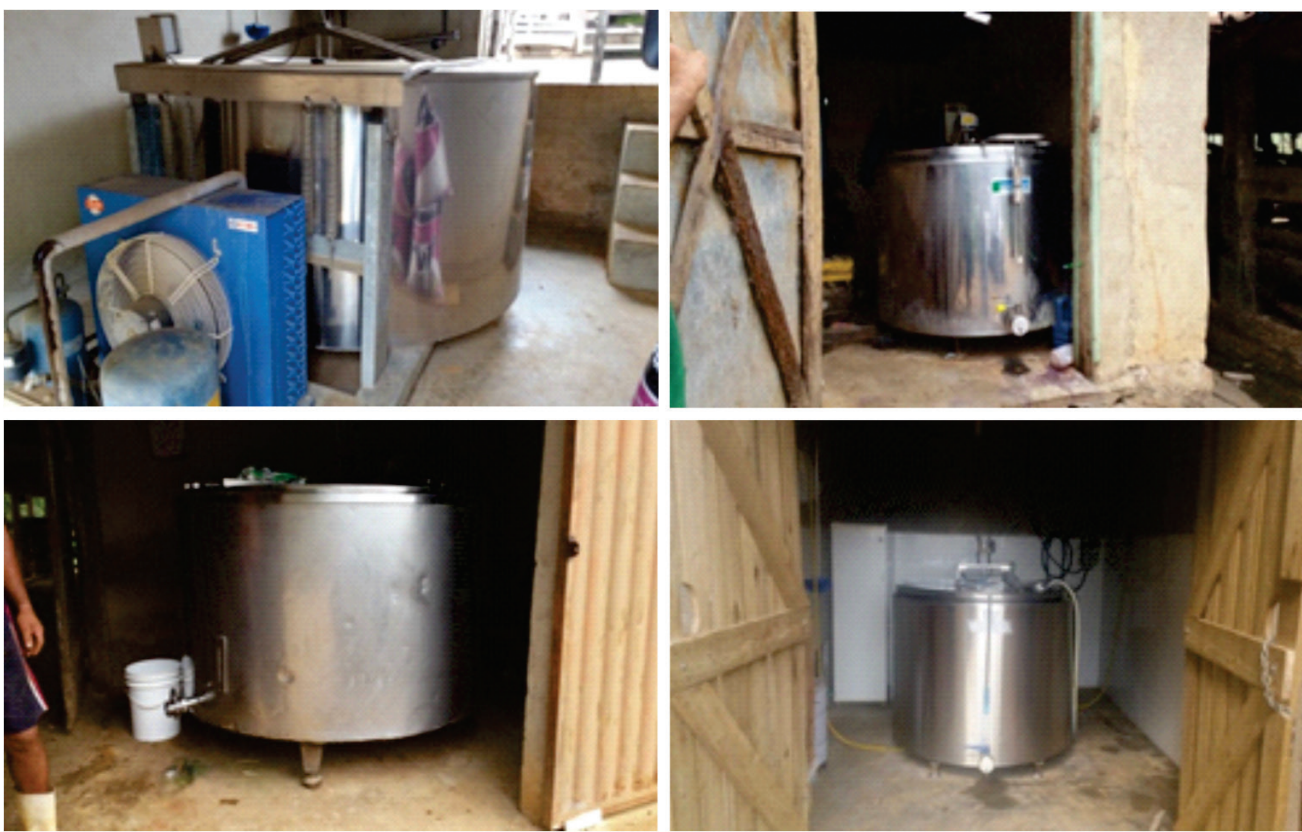

Figura 4 - Imagens de tanques distintos de granelização onde foram coletadas amostras de leite cru. Contagens médias de microrganismos mesófilos aeróbios para cada tanque: (A) 6,0 Log UFC/mL, (B) 6,0 Log UFC/mL, (C) 5,6 Log UFC/mL e (D) 4,7 Log UFC/mL. (Fonte: Patrícia Rodrigues Condé, 2017, arquivo pessoal). 
psicrotróficos superiores a 6,0 Log UFC/mL, considerando o comprometimento da integridade das proteínas e lipídeos e, consequentemente, perdas de qualidade e rendimento no processo produtivo. No outono, mais da metade das amostras tiveram contagens de microrganismos psicrotróficos superiores a 6,1 Log UFC/mL, seguidas do verão, primavera e inverno, com 33,3\%, 26,7\% e $26,7 \%$, respectivamente (Figura $3 b$ ).

Para microrganismos psicrotróficos proteolíticos (Figura 3c), as amostras coletadas no verão se destacaram por apresentar baixa contagem, $80 \%$ entre 2,0 a 4,0 Log UFC $/ \mathrm{mL}$. Em contrapartida, no inverno, 53,3\% das amostras alcançaram contagens entre 5,1 a 6,0 Log UFC/mL e 20\% apresentaram contagens acima de 6,1 Log UFC/mL (Figura $3 \mathrm{c})$. No outono, $26,7 \%$ das amostras tiveram contagens acima de 6,1 Log UFC/mL. Embora não haja na legislação brasileira limites para a presença desses grupos microbianos, Cousin (1982), Pinto et al., (2014) e Batista (2015) afirmaram que contagens de microrganismos psicrotróficos proteolíticos, psicrotróficos lipolíticos e psicrotróficos produtores de lectinase acima de 4,0 Log UFC/mL no leite, tornam este alimento impróprio para a produção de derivados lácteos como queijos e leite UHT, devido a presença de enzimas deterioradoras em concentração suficiente para comprometer a integridade das micelas de caseína e dos glóbulos de gordura.

As contagens de microrganismos psicrotróficos lipolíticos (Figura 3d) e de psicrotróficos produtores de lecitinase (Figura 3e) apresentaram-se acima de 4,0 Log UFC/mL em $78 \%$ e $30 \%$ das amostras, respectivamente. A presença destes grupos microbianos no leite cru promove a formação de compostos que conferem sabores desagradáveis em produtos lácteos associados à hidrólise dos triacilglicerídeos do leite, em ácidos graxos livres de cadeia curta, como o ácido butírico, capróico e caprílico. Além disso, os ácidos graxos de cadeia média, como o ácido cáprico e láurico têm maior participação na formação de sabor de sabão (CHEN; DANIEL; COOLBEAR, 2003).

Uma das lipases mais relevantes produzidas por bactérias psicrotróficas é a lecitinase, que hidrolisa a membrana dos glóbulos de gordura o que ocasiona defeitos de sabor e textura, conhecidos como leite/ creme gorduroso. No leite cru, bactérias Gram-negativas do gênero Acinetobacter, Alcaligenes, Citrobacter, Enterobacter, Flavobacterium, Klebsiella e Pseudomonas produzem esta enzima deterioradora (SHAH, 1994; PEREIRA, 2016).

Contagens acima de 4,0 Log UFC/mL para Pseudomonas ssp. (Figura 3f) foram constatadas em mais da metade das amostras, $73,4 \%, 73,3 \%$ e $60 \%$, no verão, outono e inverno, respectivamente, o que confirma o alto índice de contaminação do leite com microrganismos psicrotróficos.

Resultados maiores foram relatados por Almeida et al. (2017) para contagem de Pseudomonas ssp., uma vez que as amostras avaliadas tiveram médias entre 5,36 a 6,20 Log UFC/mL, ou seja, todas estavam acima de $10^{4} \mathrm{Log} \mathrm{UFC} / \mathrm{mL}$. Segundo os autores, as boas práticas de ordenha não foram implantadas e a má qualidade da água pode ter sido o fator responsável por estas contagens.

Pinto (2004) avaliou amostras de leite inoculadas com, aproximadamente, 4,0 Log UFC/mL de P. fluorescens que foram incubadas a $2,0,4,0,7,0$ e $10,0^{\circ} \mathrm{C}$, e constatou que as temperaturas de $2,0^{\circ} \mathrm{C}$ e 40 $4,0^{\circ} \mathrm{C}$ foram efetivas para o controle da multiplicação de $P$. fluorescens após 24 horas de incubação. Após 48 horas, a população dessa bactéria foi de 4,0 Log UFC/mL a $2,0^{\circ} \mathrm{C}, 5,0 \log \mathrm{UFC} / \mathrm{mLa} 4,0^{\circ} \mathrm{C}, 6,0 \log \mathrm{UFC} / \mathrm{mL}$ a $7,0{ }^{\circ} \mathrm{C}$ e de $7,0 \mathrm{Log} \mathrm{UFC} / \mathrm{mL}$ a $10,0{ }^{\circ} \mathrm{C}$. O autor afirmou que, mesmo nas temperaturas de refrigeração propostas pela legislação, pode ocorrer a perda de qualidade da 
matéria-prima, se não for realizado controle efetivo da contaminação inicial.

Considerando os grupos microbianos avaliados, constatou-se menores $(\mathrm{p}<0,05)$ valores de contagens para psicrotróficos produtores de lecitinase e para psicrotróficos proteolíticos nas estações primavera e verão (Tabela 1). Por outro lado, as contagens de microrganismos mesófilos aeróbios, psicrotróficos e psicrotróficos lipolíticos não diferiram $(p>0,05)$ entre si e nas estações do ano, exceto a contagem de microrganismos psicrotróficos no outono que foi maior $(\mathrm{p}<0,05)$ em relação à contagem de psicrotróficos lipolíticos no verão (Tabela 1 ).

As contagens microbianas obtidas nesse trabalho não se correlacionaram com a incidência de chuvas na região avaliada, uma vez que os índices pluviométricos fornecidos pela Companhia de Saneamento de Minas Gerais (COPASA, Rio Pomba) foram de $37,5 \mathrm{~mm}, 66,4 \mathrm{~mm}, 54,1 \mathrm{~mm}$ e $6,8 \mathrm{~mm}$, respectivamente, no período de coleta das estações primavera, verão, outono e inverno. Portanto, mesmo com índice pluviométrico maior no verão do que nas outras estações,

Tabela 1 - Contagem média $(\mathrm{n}=15)$ de microrganismos mesófilos aeróbios, psicrotróficos, psicrotróficos proteolíticos, psicrotróficos lipolíticos e de psicrotróficos produtores de lecitinase nas estações do ano

\begin{tabular}{lcc}
\hline Grupo microbiano & Estação do ano & Log UFC/mL \\
\hline \multirow{2}{*}{ Mesófilos aeróbios } & Primavera & $5,5 \pm 0,88^{\text {cde }}$ \\
& Verão & $5,3 \pm 0,70^{\text {cde }}$ \\
& Outono & $5,3 \pm 0,87^{\text {cde }}$ \\
& Inverno & $4,6 \pm 0,87^{\text {bcde }}$ \\
\hline Psicrotróficos & Primavera & $5,4 \pm 1,0^{\text {cde }}$ \\
& Verão & $5,7 \pm 0,89^{\text {de }}$ \\
Psicrotróficos proteolíticos & Outono & $6,1 \pm 1,37^{\mathrm{e}}$ \\
& Inverno & $5,7 \pm 1,20^{\text {de }}$ \\
\hline Psicrotróficos lipolíticos & Primavera & $3,5 \pm 0,80^{\text {ab }}$ \\
& Verão & $4,1 \pm 1,70^{\text {bc }}$ \\
& Outono & $5,0 \pm 1,62^{\text {bcde }}$ \\
& Inverno & $5,2 \pm 1,56^{\text {cde }}$ \\
\hline & Primavera & $4,8 \pm 1,13^{\text {bcde }}$ \\
& Verão & $4,4 \pm 1,56^{\text {bcd }}$ \\
& Outono & $5,3 \pm 1,51^{\text {cde }}$ \\
& Inverno & $5,2 \pm 1,32^{\text {cde }}$ \\
\hline
\end{tabular}

Médias seguidas de mesma letra na coluna não diferem entre si pelo teste de Tukey $(\mathrm{p}<0,05)$. 
as contagens microbianas foram mais baixas, não sendo este, o fator interferente nos resultados obtidos.

A alta contaminação microbiana nas amostras de leite cru refrigerado pode estar associada a procedimentos inadequados de higienização no sistema de produção, considerando que resíduos de leite constituem fontes de nutrientes para a multiplicação de bactérias e formação de biofilmes. A microbiota contaminante também pode ser adquirida durante os processos que antecedem o resfriamento ou até mesmo proveniente do tanque de refrigeração se houver má higienização dos equipamentos ou utilização de água contaminada para a limpeza (SEQUETTO et al., 2017).

\section{CONCLUSÕES}

A maioria das amostras de leite cru granelizado apresentou temperaturas médias em desacordo com a legislação brasileira. A elevada contagem de microrganismos mesófilos aeróbios com $42 \%$ das amostras fora dos padrões legais, foi um resultado indicativo de baixas condições higiênicosanitárias praticadas na obtenção de leite cru no município de Rio Pomba, MG, o que compromete sua inocuidade e integridade ao processamento. As altas contagens de microrganismos psicrotróficos, deterioradores e de Pseudomonas sp., mesmo em temperatura de refrigeração, reforçam a possibilidade de comprometimento da qualidade e estabilidade dos derivados lácteos ao longo de sua vida útil.

Portanto, é necessário que sejam realizadas nas propriedades rurais, treinamento, implementação e monitoramento contínuo de boas práticas para prevenir a contaminação e multiplicação microbiana no leite, além do controle rigoroso da temperatura desse alimento nos tanques de expansão, bem como do tempo de armazenamento do mesmo.

\section{AGRADECIMENTOS}

À Fundação de Amparo à Pesquisa de Minas Gerias (FAPEMIG - Processo CAG - APQ-03644-14), ao Instituto Federal do Sudeste de Minas Gerais, campus Rio Pomba e ao grupo PET Ciências Agrárias (Edital n. ${ }^{\circ}$ 09/2010) pelo apoio financeiro.

\section{REFERÊNCIAS}

ALMEIDA, K. M. et al. Pseudomonas spp. and $P$. fluorescens: population in refrigerated raw milk. Ciência Rural, Santa Maria, v. 47, n. 1, p. 1-6. 2017.

BATISTA, C. S. Estudo de correlação entre a qualidade do leite cru refrigerado e do leite UHT integral. 2015. 46f. Dissertação (Mestrado Profissional em Ciência e Tecnologia de Alimentos), Instituto Federal do Sudeste de Minas Gerais, Rio Pomba, 2015.

BERSOT, L. S. et al. Quantificação de microrganismos indicadores de qualidade em leite cru e comportamento da microbiota ao longo do transporte. Revista do Instituto de Laticínios Cândido Tostes, v. 65, n. 373, p. 9-13, 2010.

BRASIL. Ministério da Agricultura, Pecuária e Abastecimento. Departamento de Inspeção de Produtos de Origem Animal. Instrução Normativa n. ${ }^{\circ}$ 07, de 03 de maio de 2016. Prorroga por dois anos a vigência dos prazos estabelecidos para a adoção dos limites microbiológicos e de células somáticas, que entrariam em vigor a partir de 01 de julho de 2016 para as regiões Sul, Sudeste e CentroOeste, dispostos na Instrução Normativa n. ${ }^{\circ}$ 62, de 29 de dezembro de 2011. Diário Oficial da República Federativa do Brasil, Brasília, 03 de maio de 2016.

BRASIL. Ministério da Agricultura, Pecuária e Abastecimento. Departamento de Inspeção de Produtos de Origem Animal. Instrução 
Normativa n. ${ }^{\circ} 31$, de 29 de junho de 2018. Regulamento Técnico de Produção, Identidade e Qualidade do Leite tipo A, o Regulamento Técnico de Identidade e Qualidade de Leite Cru Refrigerado, o Regulamento Técnico de Identidade e Qualidade de Leite Pasteuriza-do e o Regulamento Técnico da Coleta de Leite Cru Refrigerado e seu Transporte a Granel, alterada pela Instrução Normativa $n^{\circ} 7$, de 3 de maio de 2016. Diário Oficial da República Federativa do Brasil, Brasília, 02 de julho de 2018b.

BRASIL. Ministério da Agricultura, Pecuária e Abastecimento. Departamento de Inspeção de Produtos de Origem Animal. Instrução Normativa n. ${ }^{\circ}$ 32, de 30 de junho de 2011. Prorroga por seis meses a vigência dos prazos estabelecidos para a adoção de novos limites microbiológicos e de células somáticas, que entrariam em vigor a partir de 01 de julho de 2011 para as regiões Sul, Sudeste e CentroOeste, dispostos na Instrução Normativa n. ${ }^{\circ}$ 51, de 18 de setembro de 2002. Diário Oficial da República Federativa do Brasil, Brasília, 01 de julho de 2011b.

BRASIL. Ministério da Agricultura, Pecuária e Abastecimento. Departamento de Inspeção de Produtos de Origem Animal. Instrução Normativa n. ${ }^{\circ}$ 51, de 18 de setembro de 2002. Regulamentos Técnicos de Produção, Identidade e Qualidade do Leite tipo A, do Leite tipo B, do Leite tipo C, do Leite Pasteurizado e do Leite Cru Refrigerado e o Regulamento Técnico da Coleta de Leite Cru Refrigerado e seu Transporte a Granel. Diário Oficial da República Federativa do Brasil, Brasília, 20 de setembro de 2002.

BRASIL. Ministério da Agricultura, Pecuária e Abastecimento. Departamento de Inspeção de Produtos de Origem Animal. Instrução Normativa $n .^{\circ}$ 62, de 29 de dezembro de 2011. Altera o caput... da Instrução Normativa n. ${ }^{\circ} 51$ de setembro de 2002. Coleta de leite cru refrigerado e seu transporte a granel. Coleta de leite cru refrigerado e seu transporte a granel. Diário Oficial da República Federativa do Brasil, Brasília, 30 de dezembro de 2011a.

BRASIL. Ministério da Agricultura, Pecuária e Abastecimento. Departamento de Inspeção de Produtos de Origem Animal. Instrução Normativa n. ${ }^{\circ} 76$, de 26 de novembro de 2018. Aprova os Regulamentos Técnicos que fixam a identidade e as características de qualidade que devem apresentar o leite cru refrigerado, o leite pasteurizado e o leite pasteurizado tipo A. Diário Oficial da República Federativa do Brasil, Brasília, 30 de novembro de 2018 a.

BRITO, M. A. P. Identificando fontes e causas de alta contagem bacteriana total do leite do tanque. Panorama de Leite On-Line, Minas Gerais, v. 4, n. 40, mar. 2010. Disponível em: $<$ www.cileite.com.br/panorama/especial40. html>. Acesso em: 21 de maio de 2018.

CANUTO, J. W. et al. Efeito da microbiota psicrotrófica e mesofílica contaminante do leite cru e pasteurizado na qualidade do leite UHT. In: CAMPOS, A. N. R. et al. Ciência e Tecnologia no Campus Rio Pomba do IF Sudeste MG: contribuições para a Zona da Mata Mineira. Rio Pomba, $1^{\text {a }}$ ed., p. 89111, 2016. Disponível em: <https://sistemas. riopomba.ifsudestemg.edu.br/dppg/index. php? arquivo=conteudo_menu_categoria php\&codigo_subcategoria $=45>$. Acesso em: 21 de maio de 2018 .

CHEN, L.; DANIEL, R. M.; COOLBEAR, $\mathrm{T}$. Detection and impact of protease and lipase activities in milk and milk powders. International Dairy Journal, v. 13, p. 255275, 2003.

COSTA, J. F. Atributos de qualidade associados à ocorrência de proteólise em leite cru granelizado. 2014. $111 \mathrm{f}$. Dissertação (Mestrado Profissional em Ciência e Tecnologia do Leite e Derivados), 
Universidade Federal de Juiz de Fora, Juiz de Fora, 2014.

COUSIN, M. A. Presence and activity of psychrotrophic microrganisms in milk and dairy products: a review. Journal of Food Protection, v. 45, p. 172-207, 1982.

COUSIN, M. A.; BRAMLEY, A. J. The microbiology of raw milk. In: Robinson, R. K. (Ed). Dairy Microbiology of Milk. $4^{\mathrm{a}} \mathrm{ed}$. Applied Science Publishers, London, v. 1, 1981, p. 119-163.

COUSIN, M. A.; JAY, J. M.; VASAVADA, P. C. Psychrotrophic microrganisms. In: DOWNES, F. P.; ITO, K., (Eds). Compendium of methods for the microbiological examination of foods. $4^{\mathrm{a}}$ ed. Washington DC: American Public Health Association APHA, Chapter 13, 2001, p. 159-166.

HAAS, M. J. Lipolytic Microorganisms. In: DOWNES, F. P.; ITO, K., (Eds). Compendium of methods for the microbiological examination of foods. $4^{\mathrm{a}}$ ed. Washington DC: American Public Health Association APHA, Chapter 15, 2001, p. 175-180.

MACHADO, S. G. et al. The biodiversity of the microbiota producing heat-resistant enzymes responsible for spoilage in processed bovine milk and dairy products. Frontiers in Microbiology, v. 8, p. 1-22, 2017.

MARCY, J. A.; PAYTON PRUETT, W. Jr. Proteolytic Microorganisms. In: DOWNES, F. P.; ITO, K., (Eds). Compendium of methods for the microbiological examination of foods. $4^{\mathrm{a}}$ ed. Washington DC: American Public Health Association - APHA, Chapter 16, 2001, p. 183-186.

MORTON, R. D. Aerobic Plate Count. In: DOWNES, F. P.; ITO, K., (Eds). Compendium of methods for the microbiological examination of foods. $4^{\mathrm{a}}$ ed. Washington
DC: American Public Health Association APHA, Chapter 7, 2001, p. 63-67.

OLIVEIRA, G. B. et al. Psychrotrophic bacteria in milk: How much do we really know? Brazilian Journal of Microbiology, v. 46, n. 2, p. 313-321, 2015.

PEREIRA, F. A. B. Capacidade lipolítica de Pseudomonas fluorescens e Pseudomonas putida isoladas do leite cru refrigerado. 2016. 61f. Dissertação (Mestrado em Ciência e Tecnologia de Leite e Derivados), Universidade do Norte do Paraná - UNOPAR, Londrina, 2016.

PINTO, C. L. O. Bactérias psicrotróficas proteolíticas do leite cru resfriado granelizado usado para produção de leite UHT. 2004. 97f. (Microbiologia Agrícola), Universidade Federal de Viçosa, Viçosa, 2004.

PINTO, C. L. O. et al. Proteolytic potential of Pseudomonas fluorescens isolated from refrigerated raw milk. Revista Brasileira de Agropecuária Sustentável, v. 4, n. 2, p. 16-25, 2014.

RIBEIRO NETO, A. C. et al. Qualidade do leite cru refrigerado sob Inspeção Federal na região Nordeste. Arquivo Brasileiro de Medicina Veterinária e Zootecnia, v. 64, n. 5, p. 1343-1351, 2012.

SEQUETTO, P. L. et al. Avaliação da qualidade microbiológica de leite cru refrige-rado obtido de propriedades rurais da Zona da Mata mineira. Revista Brasileira de Agropecuária Sustentável (RBAS), v. 7, n. 1, p. 42-50, 2017.

SHAH, N. P. Psychrotrophs in milk: a Review. Milchwissenschaft, v. 49, n. 8, p. 432-437, 1994.

TIBCO, software estatística (data analyses software system), version 13. <http:// statistica.io>, 2017. 